\title{
Estimated Impact of US Preventive Services Task Force Recommendations on Use and Cost of Statins for Cardiovascular Disease Prevention
}

\author{
Quyen Ngo-Metzger, MD, MPH, Samuel H. Zuvekas, PhD, and Arlene S. Bierman, MD, MS \\ Agency for Healthcare Research and Quality, U.S. Department of Health and Human Services, Rockville, MD, USA.
}

BACKGROUND: US Preventive Services Task Force (USPSTF) released new recommendations on statin use for atherosclerotic cardiovascular disease (ASCVD) prevention. The Affordable Care Act (ACA) mandates USPSTF recommendations with an " $A$ " or " $B$ " grade receive insurance coverage without copayment. We assessed the potential impact of these recommendations.

OBJECTIVE: To assess the US population meeting criteria for statin use and factors associated with use, and calculate associated costs.

DESIGN AND MEASURES: We estimated 10-year ASCVD event risk scores from National Health and Nutrition Examination Survey data using Pooled Cohort Equations from the American College of Cardiology/American Heart Association and applied them to Medical Expenditure Panel Survey data. We estimated the population meeting USPSTF criteria and calculated the number of statin prescription fills and out-of-pocket and total costs. We assessed associations between statin use and sociodemographic and health characteristics and national trends in use from 1996 to 2014.

PARTICIPANTS: A nationally representative sample of people aged $\geq 40$ years, representing 150 million people living in the USA.

KEY RESULTS: Of 26.8 million adults recommended for statins, only $41.8 \%$ were taking them. Female sex, Hispanic ethnicity, uninsured status, or living in the South was associated with lower odds of using statins. Under ACA, people with private insurance would avoid out-ofpocket cost of $\$ 9$ for each generic prescription, resulting in savings of approximately \$44 in annual costs. ACA's mandate for insurance coverage would result in a \$193 million shift in out-of-pocket cost for statins from patients to private insurers.

CONCLUSIONS: New USPSTF recommendations may result in decreased out-of-pocket costs and expanded access to statins. Previous research has shown that eliminating copayments increased adherence and decreased rates of ASCVD events without increasing overall

The opinions stated in this paper are those of the authors and are not that of the Agency for Healthcare Research and Quality (AHRQ) nor the US Department of Health and Human Services.

Electronic supplementary material The online version of this article (https://doi.org/10.1007/s11606-018-4497-4) contains supplementary material, which is available to authorized users.

Received August 23, 2017

Revised January 26, 2018

Accepted May 11, 2018

Published online May 31, 2018 healthcare costs. Future research will determine whether the USPSTF's recommendations will result in similar findings.

KEY WORDS: prevention; statin; cholesterol; cardiovascular; cost.

J Gen Intern Med 33(8):1317-23

DOI: $10.1007 / \mathrm{s} 11606-018-4497-4$

(C) Society of General Internal Medicine (This is a U.S. Government work and not under copyright protection in the US; foreign copyright protection may apply) 2018

\section{INTRODUCTION}

Atherosclerotic cardiovascular disease (ASCVD) is the leading cause of morbidity and mortality in adults aged 40 years and older, accounting for one of every three deaths in the USA. Risk factors for ASCVD include hypertension, hyperlipidemia, and smoking; approximately $47 \%$ of Americans have at least one of these three risk factors. ${ }^{1}$

Statins have been shown to be an important tool in reducing the risk of atherosclerotic cardiovascular events. In November 2016, the US Preventive Services Task Force (USPSTF) recommended statin use in adults aged 40 to 75 years without a history of ASCVD who have one or more ASCVD risk factors and a calculated 10-year ASCVD event risk of $10 \%$ or greater ("B" grade). ${ }^{2}$ The USPSTF also recommended that clinicians offer statins to adults aged 40 to 75 years without a history of ASCVD who have one or more ASCVD risk factors and a calculated 10-year ASCVD event risk of 7.5 to $10 \%$ ("C" grade for individualized decision making based on patient preferences). ${ }^{2}$ The USPSTF did not recommend for or against starting statin therapy for primary prevention in adults aged 76 years and older, citing lack of evidence to make a recommendation (I statement, or "insufficient evidence"). ${ }^{2}$ These recent USPSTF recommendations can potentially affect a large number of the US adult population and expand statin use.

The Affordable Care Act (ACA) mandates that USPSTF recommendations with an "A" or "B" grade have first-dollar insurance coverage without patient copayment, potentially resulting in many more Americans having access to statins without out-of-pocket costs. Greater out-of-pocket costs for statin medications have been associated with fewer prescriptions filled by patients and reductions in statin adherence. ${ }^{3,4}$ Zero out-of-pocket cost may induce more patients to fill their statin prescriptions. Previous research has shown that 
adherence to preventive medications increased by approximately $5 \%$ and rates of major cardiovascular events were significantly reduced with the elimination of patient copay for medications, without effects on overall healthcare cost. ${ }^{5}$ In addition to potentially increasing use, the zero cost-sharing requirements would also shift statin costs from patients to private health insurance companies.

Given the implications of these recommendations for changes in statin use and costs in the US population, we assessed the current use and cost of statins for ASCVD primary prevention and estimated the number of people in the USA for whom statin therapy would be recommended based on the new USPSTF guidelines. We further quantified the amount of current spending that would shift from patients to private insurers under the ACA preventive care mandate and discuss the potential for increased use and spending under the guidelines.

\section{METHODS}

\section{Study Population and Design}

The principal source of data was the Medical Expenditure Panel Survey (MEPS), a nationally representative longitudinal survey of the civilian, noninstitutionalized population that has been conducted by the Agency for Healthcare Research and Quality since $1996 .{ }^{5}$ The MEPS uses an overlapping panel design with a new 2-year panel beginning each year. We used MEPS data from 2014 to develop estimates of the population meeting USPSTF criteria for primary ASCVD prevention. We used MEPS data from its inception in 1996 until 2014 to describe age-adjusted trends in the use of statins in the community population aged 40 to 75 years and 76 years and older, respectively. We used 2014 data to provide estimates of current statin use and cost information, including out-of-pocket and total costs of statin treatment. We also assessed the association between statin use and sociodemographic characteristics, health status, ASCVD risk factors, health insurance status, and geographic region.

\section{Main Variables}

Estimation of the population for whom primary or secondary ASCVD prevention with statins is recommended requires three components: history of ASCVD events, ASCVD risk factors, and 10-year ASCVD event risk scores. We ascertained history of ASCVD events from household respondents' responses to being asked whether a doctor or other professional had ever told them they had coronary heart disease, angina (angina pectoris), a heart attack (myocardial infarction), or stroke or transient ischemic attack. We obtained ASCVD risk factors from similar questions regarding hypertension, high cholesterol, and diabetes, and smoking status from the MEPS Self-Administered Questionnaire (SAQ). However, because the MEPS lacks clinical blood pressure and cholesterol measurements, we predicted 10-year ASCVD event risk scores from 2011 to 2014 National Health and Nutrition Examination Survey (NHANES) data ${ }^{6}$ using the Pooled Cohort Equations from the 2013 American College of Cardiology/American Heart Association (ACC/AHA) guidelines ${ }^{7}$ and applied them to 2014 MEPS data using methods described in the online appendix. Predictions of 10-year ASCVD risk scores without clinical measurements had $86.3 \%$ sensitivity and $93.7 \%$ specificity compared to actual 10 -year ASCVD scores using clinical measurements in the NHANES. Our estimates of the proportion of the population who meets the USPSTF criteria for ASCVD primary prevention with statins based on MEPS data are quantitatively similar to and not statistically different from estimates derived from NHANES data using clinical measurements.

We identified generic and branded statin drug fills from all prescription drug fills reported in MEPS by matching to the Cerner Multum Lexicon Plus and Medi-Span Core Drug databases by National Drug Code.

Five hierarchical and mutually exclusive categories describe health insurance coverage: Medicare coverage and aged 65 years and older; Medicare coverage and younger than 65 years, indicating disability coverage; any private coverage; any Medicaid coverage; and uninsured.

\section{Analysis}

We estimated the total number and proportion of the community population aged 40 to 75 years with a history of ASCVD, indicating secondary prevention; no history of ASCVD but one or more ASCVD risk factors; and no history of ASCVD but one or more ASCVD risk factors and a 10-year ASCVD event risk score greater than $10 \%$. The latter group met USPSTF criteria for primary ASCVD prevention with statin use. We provided estimates of the population with a 10-year ASCVD event risk score greater than $7.5 \%$ and between 7.5 and $10 \%$, and estimates of the total number and proportion of people who used statins in 2014 for each of these populations. We also estimated the population with and without a history of ASCVD, with one or more ASCVD risk factors, and statin use in the community population aged 76 years and older. We further stratified population and statin use estimates by insurance coverage.

To assess the predictors of current statin use among adults needing primary ASCVD prevention, we estimated logistic regressions of the odds of any statin use in 2014. Covariates included age, sex, race/ethnicity, ASCVD risk factors, 12-Item Short-Form Health Survey physical component score from the SAQ, marital status, education level, insurance coverage, census region, and the metropolitan statistical area.

Using 2014 data, we estimated the total number of statin fills, total out-of-pocket cost, total cost, out-of-pocket and total cost per fill, and annual per-person number of fills and costs for the population meeting the criteria for the USPSTF " $B$ " recommendation. We stratified these 
Table 1 Demographic and Health Characteristics of Adults Aged 40 Years and Older with No History of ASCVD, 2014

\begin{tabular}{|c|c|c|c|c|}
\hline \multirow[t]{2}{*}{ Characteristics } & \multicolumn{2}{|c|}{ Aged $40-75$ years } & \multicolumn{2}{|c|}{ Aged $\geq 76$ years } \\
\hline & $N$ & $\begin{array}{l}\text { Weighted population } \\
\text { in millions }(95 \% \mathrm{CI})\end{array}$ & $N$ & $\begin{array}{l}\text { Weighted population } \\
(95 \% \text { CI })\end{array}$ \\
\hline Full population & 11,227 & $132.1(125.8-138.4)$ & 1352 & $17.9(16.3-19.5)$ \\
\hline Population with no history of ASCVD* & $\begin{array}{l}9762 \\
N\end{array}$ & $\begin{array}{l}115.8(110.1-121.5) \\
\text { Weighted percentage }(95 \% \mathrm{CI})\end{array}$ & $\begin{array}{l}836 \\
N\end{array}$ & $\begin{array}{l}10.7(9.5-12.0) \\
\text { Weighted percentage }(95 \% \mathrm{CI}\end{array}$ \\
\hline \multicolumn{5}{|l|}{ Age, years } \\
\hline $40-49$ & 3431 & $32.1(30.8-33.4)$ & 0 & - \\
\hline $50-59$ & 3384 & $34.8(33.5-36.2)$ & 0 & - \\
\hline $60-64$ & 1249 & $14.0(13.0-14.9)$ & 0 & - \\
\hline $65-69$ & 1002 & $10.9(10.0-11.8)$ & 0 & - \\
\hline $70-75$ & 696 & $8.2(7.3-9.0)$ & 0 & - \\
\hline $76-79$ & 0 & - & 335 & $38.0(33.4-42.5)$ \\
\hline $80-84$ & 0 & - & 273 & $34.8(30.5-39.1)$ \\
\hline$\geq 85$ & 0 & - & 228 & $27.2(23.3-31.1)$ \\
\hline \multicolumn{5}{|r|}{$210(20.0710)$} \\
\hline Women & 5395 & $52.7(51.9-53.6)$ & 528 & $63.8(60.2-67.4)$ \\
\hline Men & 4367 & $47.3(46.4-48.1)$ & 308 & $36.2(32.6-39.8)$ \\
\hline \multicolumn{5}{|l|}{ Race/ethnicity } \\
\hline Hispanic & 2466 & $13.1(11.4-14.8)$ & 125 & $7.4(5.4-9.3)$ \\
\hline Non-Hispanic white & 4251 & $67.6(65.2-70.0)$ & 457 & $77.9(74.2-81.6)$ \\
\hline Non-Hispanic black & 2028 & $11.1(9.8-12.5)$ & 157 & $8.3(6.4-10.2)$ \\
\hline Non-Hispanic Asian & 813 & $5.9(4.7-7.1)$ & 86 & $5.1(2.7-7.5)$ \\
\hline Non-Hispanic other & 204 & $2.2(1.6-2.9)$ & 11 & $1.3(0.3-2.3)$ \\
\hline \multicolumn{5}{|l|}{ Marital status } \\
\hline Unmarried & 3978 & $34.3(32.5-36.2)$ & 500 & $53.2(48.3-58.0)$ \\
\hline Married & 5784 & $65.7(63.8-67.5)$ & 336 & $46.8(42.0-51.7)$ \\
\hline \multicolumn{5}{|l|}{ Education } \\
\hline Did not complete high school & 1776 & $10.5(9.6-11.4)$ & 248 & $21.0(17.6-24.4)$ \\
\hline High school graduate/GED & 2688 & $25.8(24.4-27.2)$ & 237 & $31.6(27.0-36.1)$ \\
\hline Some college & 2743 & $29.9(28.6-31.2)$ & 178 & $24.1(20.1-28.2)$ \\
\hline College degree or higher & 2494 & $33.4(31.5-35.3)$ & 161 & $22.2(18.6-25.9)$ \\
\hline \multicolumn{5}{|l|}{ Insurance coverage } \\
\hline Medicare & 2093 & $22.5(21.2-23.7)$ & 828 & $99.1(98.2-100.0)$ \\
\hline Private & 5293 & $61.5(60.0-62.9)$ & 3 & $0.7(0.2-1.6)$ \\
\hline Medicaid & 972 & $6.4(5.5-7.2)$ & 0 & $0.0(0.00 .0)$ \\
\hline Uninsured & 1404 & $9.7(8.7-10.6)$ & 5 & $0.2(0.0-0.4)$ \\
\hline \multicolumn{5}{|l|}{ Census region } \\
\hline Northeast & 1591 & $18.3(16.7-19.9)$ & 136 & $19.8(15.0-24.6)$ \\
\hline Midwest & 1764 & $21.7(19.9-23.6)$ & 158 & $22.4(18.1-26.8)$ \\
\hline South & 3621 & $36.6(34.4-38.8)$ & 318 & $34.2(28.4-39.9)$ \\
\hline West & 2786 & $23.4(21.4-25.3)$ & 224 & $23.6(18.5-28.7)$ \\
\hline \multicolumn{5}{|l|}{ MSA } \\
\hline MSA & 8539 & $84.7(81.9-87.5)$ & 674 & $76.6(70.6-82.6)$ \\
\hline Non-MSA & 1223 & $15.3(12.5-18.1)$ & 162 & $23.4(17.4-29.4)$ \\
\hline$\geq 1$ ASCVD risk factor & 6203 & $63.6(62.1-65.1)$ & 700 & $84.1(80.9-87.4)$ \\
\hline Doctor ever told high cholesterol & 3762 & $39.9(38.5-41.4)$ & 474 & $58.1(53.7-62.5)$ \\
\hline Doctor ever told had hypertension & 3991 & $40.2(38.7-41.7)$ & 569 & $66.0(61.6-70.3)$ \\
\hline Doctor ever told had diabetes & 1299 & $11.5(10.7-12.3)$ & 182 & $17.9(14.4-21.5)$ \\
\hline Current smoker & 1489 & $14.5(13.5-15.4)$ & 51 & $5.5(3.4-7.5)$ \\
\hline
\end{tabular}

Authors' calculations from the Agency for Healthcare Research and Quality, Medical Expenditure Panel Survey, 1996-2014. https://meps.ahrq.gov/ mepsweb/survey_comp/household.jsp

*Respondent reported no when asked whether a doctor had ever told them they had CHD, MI, angina, or stroke

estimates by use of generic or brand name drug and by insurance status. In addition to the five mutually exclusive insurance categories, we estimated prescription fills and costs for people with any employer-sponsored coverage. This included $90 \%$ of people in the privately insured category, as well as many Medicare beneficiaries who either have retiree coverage or have coverage through their or their spouse's current employer.

We conducted all analyses with Stata/MP version 14 (StataCorp), using appropriate sample weights (full-year population weights for the 1996-2014 trend analysis and MEPS SAQ weights for the remaining analyses). We used the svy commands in Stata to account for the stratified and clustered design of MEPS in all standard errors, confidence intervals, and statistical tests performed, as well as mi commands for the small amount of multiple imputed data.

\section{RESULTS}

Table 1 shows the sociodemographic characteristics and health status of the study population aged 40 years and older with no history of ASCVD. Among those aged 40 to 75 years, 63.6\% (95\% CI 62.1-65.1\%) have one or more ASCVD risk factors. Among those aged 76 years and older, $84.1 \%$ (95\% CI 80.9$87.4 \%$ ) have one or more ASCVD risk factors.

Table 2 shows the populations who would be eligible for ASCVD primary prevention based on $\mathrm{USPSTF}^{2}$ or ACC/ 
Table 2 Population and Statin Use by Primary Prevention Risk Factors of Adults Aged 40 Years and Older, 2014

\begin{tabular}{|c|c|c|c|c|c|c|}
\hline & \multicolumn{3}{|c|}{ All adults aged 40 to 75 years } & \multicolumn{3}{|c|}{ Statin users, adults aged 40 to 75 years } \\
\hline & $N$ & $\begin{array}{l}\text { Weighted } \\
\text { population } \\
\text { in millions } \\
(95 \% \mathrm{CI})\end{array}$ & $\begin{array}{l}\text { Weighted } \\
\text { percentage } \\
(95 \% \text { CI) }\end{array}$ & $N$ & $\begin{array}{l}\text { Weighted users } \\
\text { in millions } \\
(95 \% \mathrm{CI})\end{array}$ & $\begin{array}{l}\text { Weighted row } \\
\text { percentage } \\
(95 \% \text { CI) }\end{array}$ \\
\hline $\begin{array}{l}\text { Full population aged } 40-75 \\
\text { years }\end{array}$ & 11,227 & $132.1(125.8-138.4)$ & 100.0 & 2652 & $33.4(31.2-35.5)$ & $25.3(24.2-26.3)$ \\
\hline No history of ASCVD & 9762 & $115.8(110.1-121.5)$ & $87.7(86.9-88.5)$ & 1860 & $24.0(22.3-25.8)$ & $20.7(19.6-21.8)$ \\
\hline No ASCVD risk factors & 3559 & $42.1(39.4-44.9)$ & $31.9(30.5-33.3)$ & 37 & $0.6(0.4-0.8)$ & $1.3(0.8-1.8)$ \\
\hline$\geq 1$ ASCVD risk factors & 6203 & $73.7(69.7-77.6)$ & $55.8(54.4-57.1)$ & 1823 & $23.5(21.8-25.1)$ & $31.8(30.3-33.3)$ \\
\hline 10 -year risk $<10 \%$ & 3920 & $46.9(44.1-49.6)$ & $35.5(34.2-36.7)$ & 912 & $12.3(11.1-13.4)$ & $26.1(24.4-27.9)$ \\
\hline 10 -year risk $\geq 10 \% *$ & 2283 & $26.8(24.9-28.6)$ & $20.3(19.3-21.3)$ & 911 & $11.2(10.2-12.3)$ & $41.8(39.3-44.4)$ \\
\hline 10 -year risk $\geq 7.5 \%{ }^{\dagger}$ & 2981 & $35.2(32.9-37.5)$ & $26.7(25.6-27.7)$ & 1104 & $13.7(12.5-15.0)$ & $39.0(36.7-41.3)$ \\
\hline 10 -year risk $\geq 7.5 \%$ to $\leq 10 \%{ }^{\dagger}$ & 698 & $8.5(7.5-9.4)$ & $6.4(5.8-7.0)$ & 193 & $2.5(2.0-3.0)$ & $30.0(25.5-34.4)$ \\
\hline 10 -year risk $\geq 7.5 \%$ & 3359 & $40.2(37.6-42.8)$ & $30.5(29.3-31.6)$ & 1115 & $13.9(12.7-15.2)$ & $34.6(32.5-36.8)$ \\
\hline Statin not recommended ${ }^{\S}$ & 4425 & $52.4(49.4-55.4)$ & $39.7(38.3-41.1)$ & 57 & $0.7(0.5-1.0)$ & $1.4(1.0-1.8)$ \\
\hline Full population aged $\geq 76$ years & 1352 & $17.9(16.3-19.5)$ & 100.0 & 639 & $8.8(7.9-9.8)$ & $49.3(45.7-52.9)$ \\
\hline No history of ASCVD & 836 & $10.7(9.5-12.0)$ & $59.8(56.5-63.1)$ & 325 & $4.2(3.5-4.9)$ & $39.3(34.7-43.9)$ \\
\hline No ASCVD risk factors & 136 & $1.7(1.3-2.1)$ & $9.5(7.4-11.5)$ & 6 & $0.1(0.0-0.2)$ & $5.4(0.6-10.3)$ \\
\hline$\geq 1$ ASCVD risk factors & 700 & $9.0(7.9-10.1)$ & $50.3(47.0-53.7)$ & 319 & $4.1(3.5-4.8)$ & $45.7(40.9-50.5)$ \\
\hline
\end{tabular}

Authors' calculations from the Agency for Healthcare Research and Quality, Medical Expenditure Panel Survey, 1996-2014. https:/meps.ahrq.gov/ mepsweb/survey_comp/household.jsp

* Meets criteria for USPSTF " $B$ " grade recommendation

"Meets criteria for USPSTF " $C$ " grade recommendation

${ }^{*}$ Meets criteria for ACC/AHA treatment guidelines

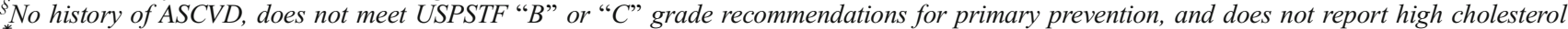

${ }^{*}$ Weighted row percentage $=$ weighted users in millions/weighted population in millions

$\mathrm{AHA}^{8}$ recommendations and who currently use statins for primary prevention.

\section{Eligibility for Statin Use}

An estimated 26.8 million people (95\% CI 24.9-28.6 million) would be eligible for statins based on the USPSTF "B" recommendation $(\geq 1$ ASCVD risk factors and a calculated 10-year ASCVD event risk $\geq 10 \%$ ). An additional 8.5 million people (95\% CI 7.5-9.4 million) could be offered statins because they have one or more ASCVD risk factors and a calculated 10-year ASCVD event risk of 7.5\% or greater ("C" recommendation). In total, approximately 35.2 million people (95\% CI 32.9-37.5 million) would be eligible for statins based on the USPSTF recommendations. In contrast, 40.2 million people (95\% CI 37.6- 42.8 million) aged 40 to 75 years would be eligible for statin use based on the ACC/AHA guidelines (calculated 10-year ASCVD event risk $\geq 7.5 \%$, regardless of ASCVD risk factors).

\section{Current Statin Use and Cost}

Among people eligible for statin use for primary prevention (based on the USPSTF "B" recommendation), only 11.2 million (95\% CI 10.2-12.3 million) (41.8\%) were using statins (Table 2). Among 17.9 million people aged 76 years and older, 10.7 million (95\% CI 9.5-12.0 million) reported no prior history of ASCVD. Because age is a major factor in calculating ASCVD risk, everyone in this population had a risk score greater than $10 \%$, and $45.7 \%$ (95\% CI, $40.9 \%-$ $50.5 \%$ ) were using statins.
Table 3 shows the adjusted odds of statin use associated with various sociodemographic and health status characteristics. Statin use for ASCVD primary prevention was more likely with higher age and among people who reported having high cholesterol (odds ratio [OR] 34.5 [95\% CI 23.2-51.3]) or diabetes (OR 2.9 [95\% CI 2.2-3.8]). Female sex (OR 0.74 [95\% CI 0.56-0.99]), Hispanic ethnicity (OR 0.55 [95\% CI 0.37-0.82]), uninsured status (OR 0.51 [95\% CI 0.28-0.93]), or living in the South (OR 0.61 [95\% CI 0.40-0.93]) was associated with decreased odds of using statins for ASCVD primary prevention.

Table 4 shows the utilization patterns and cost of statin use for primary prevention in 2014 among people aged 4075 years. An estimated 58 million statin prescriptions $(95 \%$ CI 52-65 million) were filled, at a total cost of $\$ 4.2$ billion (95\% CI \$3.4-\$5.5 billion). Mean cost per prescription filled was \$73 (95\% CI \$62-\$84), and mean out-of-pocket cost per prescription was \$13 (95\% CI \$11-\$15). Approximately 86\% of filled prescriptions were generic drugs, at a total cost of $\$ 2.0$ billion (95\% CI \$1.7-\$2.4). Based on the USPSTF recommendations, people with employer-sponsored health insurance or other private coverage would avoid paying an out-of-pocket cost of $\$ 9$ (95\% CI \$8-\$10) for each generic prescription filled. This would result in savings of approximately $\$ 44$ (95\% CI \$37-\$50) in mean annual out-of-pocket costs. The total annual out-of-pocket cost savings for generic statins is \$193 million (95\% CI \$154-\$232 million) for people with private, employer-sponsored health insurance. An additional \$239 million (not shown, 95\% CI \$129-\$349 million) in outof-pocket costs would be saved annually if branded statin fills were also covered with no copayment. 
Table 3 Logistic Regression Results, Odds of Current Statin Use in Population Meeting USPTSF "B" Grade Recommendations for Primary Prevention, Adults Aged 40 to 75 Years, 2014

\begin{tabular}{|c|c|c|}
\hline \multirow[t]{2}{*}{ Characteristics } & \multicolumn{2}{|c|}{$\begin{array}{l}\text { USPSTF recommended } \\
(N=\mathbf{2 2 8 3})\end{array}$} \\
\hline & $\begin{array}{l}\text { Odds ratio } \\
(95 \% \mathrm{CI})\end{array}$ & $\begin{array}{l}p \\
\text { value }\end{array}$ \\
\hline \multicolumn{3}{|l|}{ Age, years } \\
\hline 40-49 (omitted) & _- & _- \\
\hline $50-59$ & $1.21(0.48-3.08)$ & 0.685 \\
\hline $60-64$ & $1.98(0.77-5.10)$ & 0.154 \\
\hline $65-69$ & $2.78(0.89-8.76)$ & 0.080 \\
\hline $70-75$ & $4.47(1.36-14.69)$ & 0.014 \\
\hline Female & $0.74(0.56-0.99)$ & 0.041 \\
\hline \multicolumn{3}{|l|}{ Race/ethnicity } \\
\hline Non-Hispanic white (omitted) & - & - \\
\hline Hispanic & $0.55(0.37-0.82)$ & 0.004 \\
\hline Non-Hispanic black & $1.05(0.77-1.42)$ & 0.771 \\
\hline Non-Hispanic Asian & $1.09(0.59-2.01)$ & 0.786 \\
\hline Non-Hispanic other & $0.51(0.14-1.82)$ & 0.298 \\
\hline Doctor ever told high cholesterol & $\begin{array}{l}34.50(23.20- \\
51.30)\end{array}$ & 0.000 \\
\hline $\begin{array}{l}\text { Doctor ever told had high blood } \\
\text { pressure }\end{array}$ & $1.38(1.00-1.91)$ & 0.049 \\
\hline Doctor ever told had diabetes & $2.90(2.21-3.79)$ & 0.000 \\
\hline Current smoker & $0.88(0.61-1.26)$ & 0.476 \\
\hline SF-12 Physical component score & $1.00(0.99-1.01)$ & 0.784 \\
\hline Married & $0.98(0.74-1.30)$ & 0.905 \\
\hline \multicolumn{3}{|l|}{ Education } \\
\hline Did not complete high school (omitted) & - & - \\
\hline High school graduate/GED & $0.82(0.53-1.26)$ & 0.358 \\
\hline Some college & $0.72(0.47-1.10)$ & 0.130 \\
\hline College degree or higher & $0.77(0.45-1.29)$ & 0.315 \\
\hline \multicolumn{3}{|l|}{ Insurance coverage } \\
\hline Private (omitted) & - & _ \\
\hline Medicare & $1.26(0.69-2.28)$ & 0.446 \\
\hline Medicaid & $1.25(0.66-2.38)$ & 0.486 \\
\hline Uninsured & $0.51(0.28-0.93)$ & 0.027 \\
\hline \multicolumn{3}{|l|}{ Census region } \\
\hline Northeast (omitted) & - & - \\
\hline Midwest & $0.92(0.57-1.47)$ & 0.716 \\
\hline South & $0.61(0.40-0.93)$ & 0.022 \\
\hline West & $0.69(0.44-1.10)$ & 0.117 \\
\hline MSA & $1.05(0.72-1.54)$ & 0.799 \\
\hline Constant & $0.02(0.00-0.06)$ & 0.000 \\
\hline
\end{tabular}

Reproduced with permission from Agency for Healthcare Research and Quality $^{12}$

Figure 1 shows the age-adjusted US trends for statin use among adults aged 40 to 75 years and 75 years and older, respectively, in the last 18 years. Statin use increased rapidly from the mid-1990s to the mid-2000s among adults aged 40 to 75 years, and to the late-2000s among adults aged 75 years and older. However, statin use has leveled off in the last decade; approximately $25 \%$ of adults aged 40 to 75 years and $45 \%$ of adults aged 75 years and older used statins in recent years, despite the availability of generic versions of pravastatin (2006) and atorvastatin (2012) and publication of the ACC/ AHA guidelines in 2013.

\section{DISCUSSION}

\section{Benefits of Statins}

The USPSTF recommends statin use for the prevention of heart attacks and strokes because it is one of the few classes of medications shown not only to decrease the risk of these major health outcomes but also to decrease the risk of death overall. ${ }^{2}$ Previous studies have shown that increased adherence to statins results in decreased rates of ASCVD events such as heart attacks and strokes in people at high risk. ${ }^{9}$ Thus, some public and private insurers have either eliminated or decreased the copayment for statins for patients with a history of ASCVD as an incentive to increase patient adherence. ${ }^{3,9,10}$ However, insurers usually eliminate or decrease the copayment for statins for secondary prevention in patient populations who have had a previous heart attack or stroke. The elimination of the copayment for statins for primary prevention in a general adult population without previous ASCVD history could result in the expansion of its use and costs.

\section{Potentially Expanded Use in the General Adult Population for Primary Prevention}

In this study of a nationally representative sample of people aged 40 years and older, we found that the new USPSTF recommendations result in approximately 26.8 million people being recommended for statin use for primary prevention ("B" recommendation) and another 8.5 million being offered statins ("C" recommendation). Approximately 5 million fewer people are eligible for primary prevention using USPSTF criteria compared to that of the ACC/AHA. Among those meeting USPSTF criteria for ASCVD primary prevention, less than half are currently using statins. Female sex, Hispanic ethnicity, and uninsured status are independently associated with lower odds of statin use for ASCVD primary prevention. These results point to the potential to expand the use of statins in the general population (and also among women, racial/ethnic minorities, and those who are uninsured), in order to decrease health disparities and decrease the morbidity and mortality associated with ASCVD.

\section{Medication Copayment, Patient Adherence, and Cost}

Eliminating patient copayments for statins and other ASCVD preventive medications has been shown to increase medication adherence and decrease rates of major ASCVD events without increasing overall healthcare costs. ${ }^{9}$ This effect has been found for both secondary and primary prevention. ${ }^{9-11}$

Under the Affordable Care Act's preventive care mandate, copayments for statins would be eliminated for people with private insurance who meet the criteria of the USPSTF " $\mathrm{B}$ " recommendation for ASCVD primary prevention. Among people with private, employer-sponsored coverage, approximately \$193 million in costs would shift from patients to private insurers as currently mandated by the ACA (assuming generic prescription fills only; up to $\$ 432$ million if branded prescriptions also had no copayment). In comparison, total premiums for employer-sponsored coverage were $\$ 602$ billion in $2014,{ }^{12}$ suggesting that any potential increase in per-person premium cost among those meeting the USPSTF 
Table 4 Number of Statin Fills, Out-of-Pocket and Total Costs, Adults Aged 40 to 75 Years, 2014

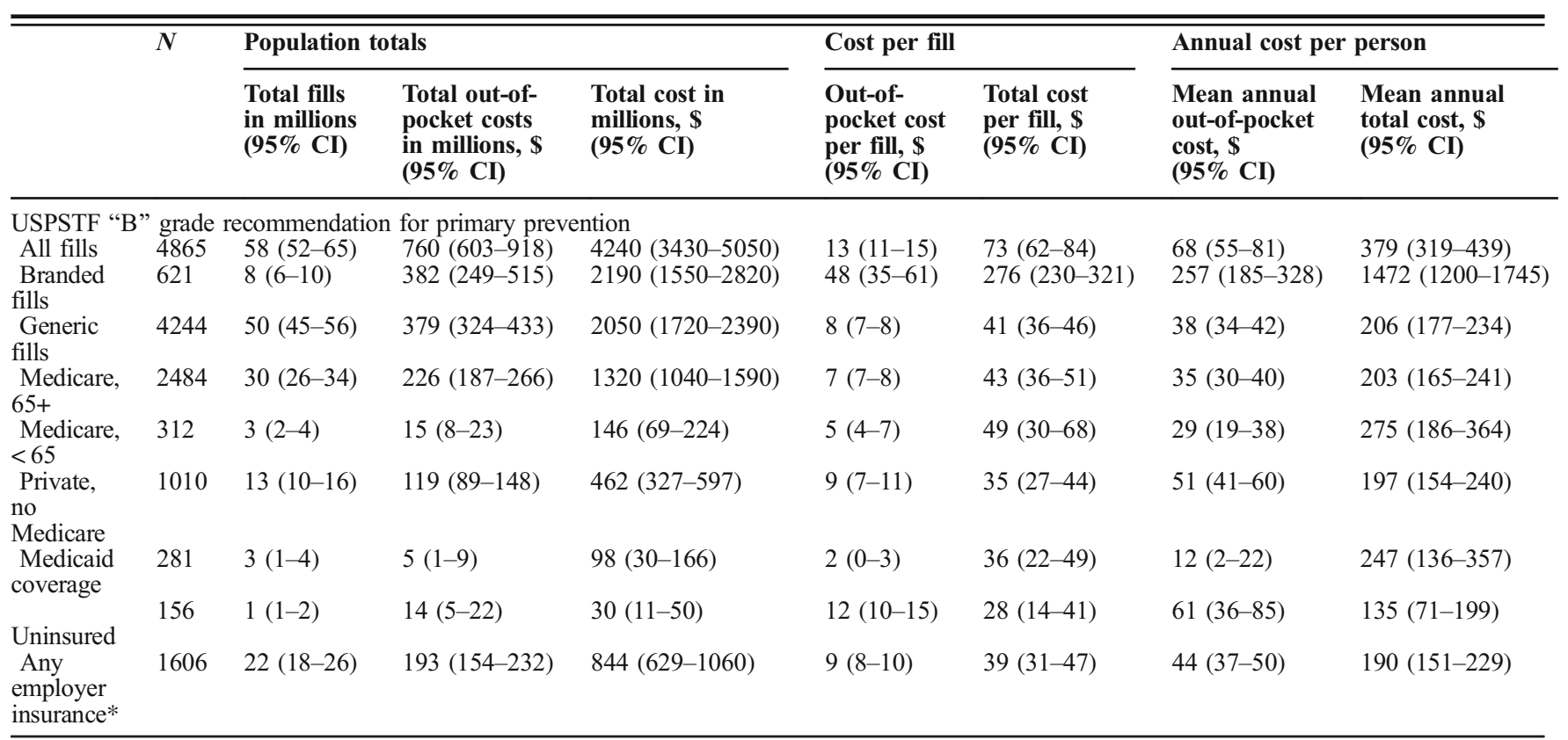

Reproduced with permission from Agency for Healthcare Research and Quality ${ }^{12}$

$*$ Any employer-sponsored insurance includes $90 \%$ of the private, no Medicare population and the Medicare population with either retiree coverage or coverage through a current job

recommendation criteria would likely be negligible. These cost increases may be offset by reductions in future medical costs due to lower morbidity from statin use. ${ }^{9}, 10,13,14$

Trends from the last 18 years have shown a leveling off in statin use, despite its potential benefit to decrease the risks for heart attacks, strokes, and death. MEPS data (Fig. 1) showing patterns of statin use in the past 18 years suggest that the 2013

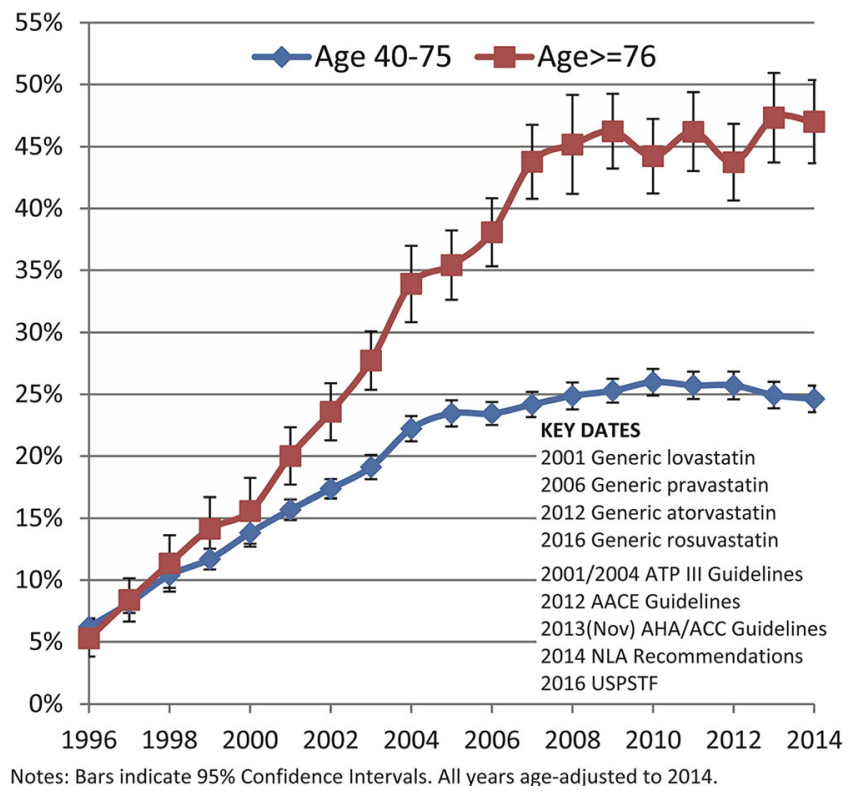

Fig. 1 Percentage of Adults Using Statins, 1996-2014. Authors' calculations from the Agency for Healthcare Research and Quality, Medical Expenditure Panel Survey, 1996-2014. https://meps.ahrq. gov/mepsweb/survey_comp/household.jsp. All years age-adjusted to 2014 age distribution.
AHA/ACC guidelines may have had minimal effects on actual statin use. Reported statin use remained unchanged between 2013 and 2014 in MEPS, and industry data from the IMS Institute for Healthcare Informatics show actual declines in the total number of prescription fills for lipid-lowering agents (from 264 million in 2013 to 260 million in 2015). ${ }^{15}$ In fact, IMS projects further reductions in statin costs with the approval of a generic version of rosuvastatin in 2016. Thus, the effect of the new USPSTF recommendations on total costs for insurers is likely to be modest. ${ }^{15}$ Additionally, increased uptake of nonpharmacologic interventions (such as healthful diet or physical activity) to modify ASCVD risk could potentially reduce the number of people who choose statin use for primary prevention.

\section{Primary ASCVD Prevention in Adults Aged 76 Years and Older}

The USPSTF concluded that there is insufficient evidence to recommend initiation of statin therapy for ASCVD primary prevention among adults aged 76 years and older. ${ }^{2}$ Decision making about the use of clinical preventive services in this population is complex and requires consideration of health and functional status, life expectancy, patient goals and preferences, and treatment burden, including polypharmacy. ${ }^{16,} 17$ Underuse of effective interventions among older adults who are healthy and overuse among those who are frail is of concern. Guidance is also needed on when to stop using a previously indicated statin medication when it is no longer likely to produce benefit. As the general population ages, there is increased need for evidence and tools to inform decision making in older adults. 


\section{Limitations}

There are limitations to our analysis. MEPS is nationally representative of the civilian noninstitutionalized population and therefore excludes active-duty military personnel, people residing in nursing homes or other long-term healthcare institutions, and people in jail or prison. ASCVD history and risk factors in MEPS are based on self-report of current smoking status and household report of whether a doctor has ever told respondents that they have various health conditions. Recall bias as well as lack of awareness of risk among some individuals may result in people underreporting their risks. Similarly, statin use and prescription fills in MEPS are based on household-reported data combined with data provided by household-reported pharmacies, which may be subject to error. Importantly, total prescription fills for lipid-lowering agents reported in MEPS correspond with industry estimates. ${ }^{15}$ Finally, our method of estimating 10-year ASCVD risk scores in the MEPS was accurate but not perfect.

\section{Conclusions}

Based on the new USPSTF recommendations, an estimated 26.8 million people are recommended for ASCVD primary prevention with statins, and an additional 8.5 million people may be offered statin use, with modest associated costs. The actual changes in use and cost will depend on uptake of the USPSTF's recommendations in clinical practice. However, the elimination of out-of-pocket cost due to the Affordable Care Act's mandate may remove patients' financial barriers to statin adherence and increase use.

Corresponding Author: Quyen Ngo-Metzger, MD, MPH; Agency for Healthcare Research and Quality, U.S. Department of Health and Human Services, Rockville, MD, USA (e-mail: quyen.ngometzger@ahrq.hhs.gov).

Funding Information This work is funded by the intramural research program at $A H R Q$.

\section{Compliance with Ethical Standards:}

Conflict of Interest: The authors declare that they have no conflicts of interest.

\section{REFERENCES}

1. Fryar CD, Chen TC, Li X. Prevalence of uncontrolled risk factors for cardiovascular disease: United States, 1999-2010. NCHS Data Brief 2012;(103): 1-8
2. U.S. Preventive Services Task Force. Statin use for the primary prevention of cardiovascular disease in adults: U.S. Preventive Services Task Force recommendation statement. JAMA 2016;316(19):1997-2007.

3. Watanabe $\mathbf{J H}$, Kazerooni R, Bounthavong $\mathbf{M}$. Association of copayment with likelihood and level of adherence in new users of statins: a retrospective cohort study. J Manag Care Pharm 2014;20(1):43-50.

4. Karaca-Mandic P, Swenson T, Abraham JM, Kane RL. Association of Medicare Part D medication out-of-pocket costs with utilization of statin medications. Health Serv Res 2013;48(4):1311-33.

5. Choudhry NK, Avorn J, Glynn RJ, et al. Post-Myocardial Infarction Free Rx Event and Economic Evaluation (MI FREEE) Trial. Full coverage for preventive medications after myocardial infarction. N Engl J Med 2011:365(22):2088-97.

6. Agency for Healthcare Research and Quality. Medical Expenditure Panel Survey HC-171: 2014 Full Year Consolidated Data File. 2016. https:// meps.ahrq.gov/data_stats/download_data/pufs/h171/h171doc.pdf. Accessed 13 April 2018

7. Centers for Disease Control and Prevention. National Health and Nutrition Examination Survey: Questionnaires, Datasets, and Related Documentation. 2015. http://www.cdc.gov/nchs/nhanes/nhanes_ questionnaires.htm. Accessed 13 April 2018.

8. Goff DC Jr, Lloyd-Jones DM, Bennett G, et al. American College of Cardiology/American Heart Association Task Force on Practice Guidelines. $2013 \mathrm{ACC} / \mathrm{AHA}$ guideline on the assessment of cardiovascular risk: a report of the American College of Cardiology/American Heart Association Task Force on Practice Guidelines. Circulation 2014;129(25 Suppl 2):S49-S73

9. Stone NJ, Robinson JG, Lichtenstein AH, et al. American College of Cardiology/American Heart Association Task Force on Practice Guidelines. 2013 ACC/AHA guideline on the treatment of blood cholesterol to reduce atherosclerotic cardiovascular risk in adults: a report of the American College of Cardiology/American Heart Association Task Force on Practice Guidelines. Circulation 2014;129(25 Suppl 2):S1-45.

10. Choudhry NK, Fischer MA, Avorn JL, et al. Impact of reducing cardiovascular medication copayments on health spending and resource utilization. J Am Coll Cardiol 2012;60(18):1817-24.

11. Bitton A, Choudhry NK, Matlin OS, Swanton K, Shrank WH. The impact of medication adherence on coronary artery disease costs and outcomes: a systematic evidence review. Am J Med 2013;126(4):357.e727.

12. Agency for Healthcare Research and Quality. 2014 Medical Expenditure Panel Survey-Insurance Component. Table IV.A.1(2014): National totals for enrollees and cost of hospitalization and physician service health plans for the private sector; United States, 2014. 2016. https://meps. ahrq.gov/data_stats/summ_tables/insr/national/series_4/2014/tival. pdf. Accessed 13 April 2018.

13. Mitchell AP, Simpson RJ. Statin cost effectiveness in primary prevention: a systematic review of the recent cost-effectiveness literature in the United States. BMC Res Notes 2012;5:373.

14. Pandya A, Sy S, Cho S, Weinstein MC, Gaziano TA. Cost-effectiveness of 10-year risk thresholds for initiation of statin therapy for primary prevention of cardiovascular disease. JAMA 2015;314(2):142-50.

15. IMS Institute for Healthcare Informatics. Medicines Use and Spending in the U.S.: A Review of 2015 and Outlook to 2020. Parsippany: IMS Institute for Healthcare Informatics; 2016.

16. Farrell B, Tsang C, Raman-Wilms L, Irving H, Conklin J, Pottie K. What are priorities for deprescribing for elderly patients? Capturing the voice of practitioners: a modified Delphi process. PLoS One 2015;10(4):e0122246.

17. Walter LC, Covinsky KE. Cancer screening in elderly patients: a framework for individualized decision making. JAMA 2001:285(21):2750-6. 